\title{
Neighborhood Socioeconomic Status and Feeding Practices in Finnish preschools
}

\section{Lehto, Reetta}

2019-07

Lehto , R , Lehto , E , Konttinen , H , Vepsalainen , H, Nislin , M , Nissinen , K, Vepsalainen , C , Koivusilta , L , Erkkola , M , Roos , E \& Ray , C 2019 , ' Neighborhood Socioeconomic Status and Feeding Practices in Finnish preschools ' , Scandinavian Journal of Public Health , vol. 47 , no. 5 , pp. 548-556 . https://doi.org/10.1177/1403494819832114

http://hdl.handle.net/10138/314218

https://doi.org/10.1177/1403494819832114

unspecified

acceptedVersion

Downloaded from Helda, University of Helsinki institutional repository.

This is an electronic reprint of the original article.

This reprint may differ from the original in pagination and typographic detail.

Please cite the original version. 
Title: Neighborhood Socioeconomic Status and Feeding Practices in Finnish preschools

\author{
Authors: \\ Reetta Lehto ${ }^{1}$, reetta.lehto@folkhalsan.fi \\ Maijaliisa Erkkola ${ }^{3}$, maijaliisa.erkkola@ helsinki.fi \\ Elviira Lehto ${ }^{1,2}$, elviira.lehto@folkhalsan.fi \\ Hanna Konttinen ${ }^{3,4}$, hanna.konttinen@ helsinki.fi \\ Henna Vepsäläinen ${ }^{3}$ henna.vepsalainen@ helsinki.fi \\ Mari Nislin ${ }^{5}$ manislin@eduhk.hk \\ Kaija Nissinen ${ }^{6}$, kaija.nissinen@seamk.fi \\ Ciara Vepsäläinen ${ }^{1}$, ciaramcbride1@gmail.com \\ Leena Koivusilta ${ }^{7}$, leena.koivusilta@utu.fi \\ Eva Roos ${ }^{1,3,8}$, eva.roos@folkhalsan.fi \\ Carola Ray ${ }^{1}$, carola.ray@ folkhalsan.fi
}

\title{
Affiliations:
}

${ }^{1}$ Folkhälsan Research Center, Helsinki, Finland

${ }^{2}$ University of Helsinki, Faculty of Educational Sciences, Helsinki, Finland

${ }^{3}$ University of Helsinki, Department of Food and Environmental Sciences, Helsinki, Finland

${ }^{4}$ University of Helsinki, Sociology, Helsinki, Finland

5 The Education University of Hong Kong, Department of Early Childhood Education, Center for Educational and Developmental Sciences, Hong Kong

${ }^{6}$ Seinäjoki University of Applied Sciences, Seinäjoki, Finland

${ }^{7}$ University of Turku, Department of Social Research, Turku, Finland

${ }^{8}$ University of Helsinki, Department of Public Health, Helsinki, Finland

Running title: Neighborhood SES and preschool feeding practices

\section{Corresponding author:}

Reetta Lehto

Folkhälsan Research Center

Topeliuksenkatu 20

00250 Helsinki, Finland

reetta.lehto@folkhalsan.fi

+358444883080 


\begin{abstract}
Aims: Certain feeding practices, such as role modelling healthy eating and encouragement are recommended to be used in preschools. Little is known about whether preschool characteristics are associated with the use of these feeding practices. Our aim was to examine whether the socioeconomic status (SES) of the preschool neighborhood is associated with the feeding practices in preschools.
\end{abstract}

Methods: This study was part of a cross-sectional DAGIS study. We studied 66 municipal preschools and 378 early childhood educators (ECEs). Preschool neighborhood SES was assessed with map grid data. Feeding practices were assessed by questionnaires and lunchtime observation. Associations between preschool neighborhood SES and feeding practices were tested with logistic regression analyses adjusted for ECEs' educational level and municipal policies on ECEs' lunch prices and birthday foods.

Results: The crude model showed that in high-SES neighborhood preschools ECEs were more likely to eat the same lunch as children (OR 2.46, 95\% CI 1.42-4.24) and to reward children with other food for eating vegetables (OR 2.48, 95\% CI 1.40-4.41). Furthermore, in high-SES preschools it was less likely that birthday foods outside the menu were available on birthdays (OR $0.29,95 \%$ CI $0.12-0.71)$. In the adjusted model, rewarding with other food remained associated with preschool neighborhood SES (OR 2.13, 95\% CI 1.12-4.07).

Conclusions: After adjustments preschool neighborhood SES was mostly unassociated with the feeding practices in preschools. Municipal policies may have a significant impact on feeding practices and ultimately on young children's food intake in Finland where most children attend municipal preschools.

Keywords: feeding practices, preschool, staff, neighborhood socioeconomic status.

Word count: 3644 


\section{BACKGROUND}

The majority $(80 \%)$ of children in countries within the Organisation for Economic Co-operation and Development (OECD) attend early childhood education, here named "preschool" [1]. In Finland 74\% of 3- to 5-year-olds attend preschool and over $90 \%$ of these children spend more than 25 hours a week in preschool [2]. Many children eat two or three meals/snacks in preschool during weekdays. Consequently, what children eat in preschool can greatly affect their energy balance, nutrient intake and the formation of eating habits. Eating habits formed in childhood often track into adulthood, which makes childhood an important period for later diet [3]. Socioeconomic differences appear early in children's diets, and in Finland, it has been found that mothers' low educational level is associated with less healthy diet among 6-year-olds [4]. Thus, preschools could have an important role in diminishing these differences.

Children's food intake in preschools is not only influenced by what is served, but also how the food is served: earlier studies have shown that children's food intake is influenced by the practices of early childhood educators (ECEs) during meals (hereafter "feeding practices") [5-7]. For example, ECEs sitting with the children and eating the same food at lunch have been associated with children's higher vegetable intake [7]. In Finland, National Nutrition Council has set meal recommendations for early childhood education and care, and these recommendations include many feeding practices [8]. Recommendations, however, are not binding. Both Finnish [8] and U.S. [9] recommendations suggest that ECEs should act as role models for healthy eating, let children serve themselves, and not use food as a reward $[8,9]$. Some studies have reported the adoption of recommended feeding practices such as ECEs sitting with children at mealtimes $[10,11]$, but discouraged practices, such as not letting children serve themselves, appear to be quite common also [7, 10, 12].

In socio-ecological models, it is argued that health behavior is influenced by factors in the immediate surroundings (such as home or childcare) which in turn interact with factors on more distal levels, such as organizational, municipal or societal level factors [13]. Thus, a topic of interest is whether some distal level factors, such as the preschool neighborhood's socioeconomic status (SES), explain differences in feeding practices between preschools. Although some studies have examined factors affecting the physical activity and feeding practices in childcare [14], to our knowledge, there are few studies on how the SES of the preschool or preschool neighborhood affects preschool feeding practices. In a British study it was found that in preschools in more deprived areas (assessed by crime and unemployment rates, housing prices, income, and educational levels) ECEs were more likely to use some recommended practices during meal times [15]. Two U.S. studies have compared preschools that are part of 
supplemental programs giving extra support for low income children (including support for healthy eating) to nonparticipant preschools and concluded that feeding practices are more aligned with the recommendations in preschools with supplemental programs [16, 17].

Finnish legislation obliges preschools to offer children full, nutritive food, but compliance to the legislation varies between municipalities and preschools. In Finland, municipalities are the basic units of local level administration, and they control preschools and many other community services. Therefore, municipalities can influence preschool feeding practices by e.g. setting own guidelines and policies, but preschools also have some liberty in deciding about meal time arrangements and practices. Children attending municipal preschools get a breakfast, warm lunch, and an afternoon snack in preschools, all provided by the municipality. Preschool groups in Finland are multidisciplinary and involve teachers, specialized teachers, nursery nurses, and assistants (here collectively called ECEs) with different educational backgrounds and duties. With different educational backgrounds, also ECEs' nutrition knowledge may vary. Overall, nutrition education for ECEs is minimal.

The objective of this study is to examine whether preschool neighborhood SES is associated with feeding practices in municipal preschool groups in Finland. We hypothesized that in such context, preschools in high SES neighborhoods might have feeding practices more aligned with official recommendations, since ECEs in high-SES neighborhood preschools may be more qualified or have more time and resources to pay attention to children's food intake due to less challenging behavior among children [18].

\section{METHODS}

This study is a secondary analysis of a cross-sectional DAGIS study, which was conducted in 2015-2016 in eight municipalities in Southern and Western Finland [19, 20]. Eight out of eleven (73\%) invited municipalities agreed to participate in the study. In order to include municipalities with socioeconomically diverse populations, municipalities were invited to the study based on their Gini coefficient, proportion of single parent households and low educated people in the municipality [21]. Also, distance from the research centers was essential. Details of the recruitment of the participants and a flow chart presenting the participation and exclusion rates have been reported previously [20]. The study received a written ethical approval by the University of Helsinki Review Board in the Humanities and Social and Behavioral Sciences, and it conforms to the principles embodied in the Declaration of Helsinki. We invited 153 preschools to participate in the study, of which 86 (56\%) gave consent. Invited preschools were randomized from all municipal preschools in the participating municipalities. Written informed consent was received from the parents 
of the preschool children. The study was conducted in 66 preschools; 20 preschools did not reach the target number of participating children (a minimum of $30 \%$ of families in at least one preschool group should have given a consent to participate in the study). In the 66 preschools, there were 161 preschool groups with mainly 3- to 6-year-old children. Of them, 159 took part in the study. Two groups did not participate because none of the children's parents in those groups gave consent.

Three data sets were used: (i) a map grid SES database on preschool neighborhoods, (ii) questionnaire data from two questionnaires provided by ECEs, and (iii) observation data on lunchtime practices.

\section{Neighborhood SES}

We assessed neighborhood SES using a grid database from Statistics Finland [22]. The database contains coordinatebased statistical data calculated on a map grid, including the area population's education, employment, and income. Population data within a one-kilometer radius from the participating preschools were used.

The score for the SES of each neighborhood was calculated using database information on (i) income (median population income in the area logarithmically transformed), (ii) educational level (percentage of over 18 year-olds whose highest educational level was a master's degree or beyond), and (iii) area unemployment rate. We coded the unemployment rate inversely in order to get higher values for lower unemployment rates. For each of the three variables, we derived a standardized z score $(M=0, S D=1)$. We then calculated the ultimate neighborhood SES score for each preschool neighborhood by taking the mean value of the $\mathrm{z}$ scores on income, educational level and unemployment rate. The score was then divided into tertiles representing low, middle, and high neighborhood SES. A variable used in another Finnish study examining health behaviors served as a model [23].

\section{Feeding practices}

Feeding practices were examined by direct observation of lunch situations and by using two questionnaires, here named as questionnaires A and B. Questionnaire A was given to all ECEs and B additionally to only one ECE per group who acted as the group's contact person. We used two separate questionnaires, because they served different purposes and it was unnecessary for several ECEs per group to answer the questions on questionnaire B.

Questionnaire A included questions on ECE's educational level and other background factors, feeding practices, and attitudes, opinion's and self-efficacy related to children's health behaviors. Altogether 378 ECEs filled in the questionnaire A, the response rate being $78 \%$. Hereafter, we numbered all used feeding practice variables from the 
two questionnaires and the observation continuously. In the analyses we used responses to questions on 1) the ECEs' knowledge of fruit and vegetable intake recommendations for children ("What do you think is the official fruit and vegetable intake recommendation for children, how many portions per day?”) (open-ended question), 2) how many times per week the ECE eats the same lunch as children (open-ended question), and 3) how often the ECE rewards children with other food for eating vegetables (with response options "never", "rarely", "sometimes", "often", “always").

Questionnaire B, which was only filled in by one ECE per group, included questions on the group's practices and mealtime arrangements which did not need to be asked from all ECEs. By having only one person to answer these questions we wanted to decrease the ECEs' respondent burden. In the analyses we used responses to a question on 4) how often children participate in practical meal preparations, e.g., setting the table (with response options "never", "1 to 5 times a year", "at least 6 times a year", "at least once a month", "at least once a week", "daily”). We also asked 5) whether there are foods available outside the menu on birthdays (response options "no", "yes, but sugary foods restricted" and "yes, sugary foods not restricted"). In total, 146 (out of 159) contact persons from 64 preschools (data from 2 preschools missing) filled in the questionnaire B (response rate 91\%).

Lunchtime feeding practices were observed by a trained researcher/research assistant. The lunchtime observation was based on four selected items from the Environment and Policy Assessment and Observation (EPAO) instrument [23], which is an observation tool to assess food and physical activity environments in preschools. Feeding practices observed during lunchtime and used in the analyses were 6) vegetable/salad serving style (did the children serve themselves or not) and 7) whether ECEs sit with the children at lunch tables. Out of 159 lunchtime situations 133 (84\%) were observed. Every group's lunch situation could not be observed due to a limited number of research personnel. Groups that were not observed ( $n=26,16 \%$ of all groups) were the groups that had the least number of children participating in the study in that preschool.

Many of the feeding practices studied are included in the meal recommendations for early childhood education and care $[8,9]$. The recommendations state that ECE's should act as role models and eat the same food as the children (feeding practices 2 and 7), and that food should not be used as a reward (feeding practice 3). Children's involvement in meal preparations is encouraged (feeding practice 4) and it is stated that children should be allowed to serve themselves (feeding practice 6). In addition, municipalities can have their own regulations on preschool food, and in 
some municipalities, children are forbidden to bring birthday treats to be served to other children at preschool (feeding practice 5).

\section{Confounders}

Based on preliminary analyses, three variables were used as confounders: 1) the ECEs' professional education, and 2) municipal policy on ECEs' lunch and 3) municipal policy on birthday treats at preschools. The question on ECEs' professional education had seven answer alternatives 1) "none", 2) "vocational qualification in social and health care [practical nurse]", 3) "bachelor of Social Services”, 4) “college-educated social pedagogue/educator", 5) “collegeeducated kindergarten teacher", 6) "bachelor's degree in education [kindergarten teacher]", and 7) "master's degree in education with specialization in early childhood education"). These were categorized into four classes presented in Table 1: 1) no qualification (1);2) vocational qualification (2); 3) bachelor of social services/social pedagogue (3 and 4); and 4) kindergarten teacher or more (5,6 and 7).

Information on municipal policies on ECEs' lunch and on children's birthday treats was retrieved from the appropriate municipal administrators by e-mail from each of the eight municipalities that participated in the study. Bringing birthday treats to preschool to serve them to other children is a common habit in Finland, but some municipalities have forbidden it. Municipalities also decide whether all or some ECEs get to eat a "model lunch" with children and thereby get the lunch by paying only the its taxable value (=a very low price), while other ECEs pay the full price, if they wish to eat the preschool food. This way the municipality can encourage one or all ECEs to eat the same lunch as the children. Municipal policies on ECEs' lunches were categorized according to whether or not all ECEs got the lunch with its taxable value. The policy on children's birthday treats was categorized according to whether or not children were allowed to bring and serve birthday treats to other children in the preschool.

\section{Statistical methods}

Chi-squared tests were used to test associations between neighborhood SES and municipal policies, and municipal policies and two feeding practices. The associations between neighborhood SES and each feeding practice variable were then analysed with logistic regression models. We used dummy variables for the neighborhood SES tertiles with low neighborhood SES as the reference category. Three logistic regression models were fitted: a first crude model with no adjustments, a second model adjusted for ECEs' educational level, and a third model that was additionally adjusted for municipal policies on ECEs' lunch and on children's birthday treats. When group level feeding practices 
were analysed, the mean educational level of the ECEs in that group was used. In logistic regression analyses, the strengths of the associations were expressed by odds ratios (OR) and 95\% confidence intervals (CI). In order to take into account the nested design of the sample, confidence intervals were adjusted for clustering at the preschool level [25]. All eligible data were used in each analysis. The $\mathrm{N}$ of the data varied because of missing values for some variables. The statistical programs IBM Statistics SPSS 21.0 and Mplus Version 7.4 were used.

\section{RESULTS}

Descriptive results are shown in Table 1. In five out of eight municipalities, all ECEs got lunches with taxable fee and in three out of eight municipalities, the children were not allowed to bring birthday treats to the preschool (not presented in tables). Cross tabulations on neighborhood SES and municipal policies on ECEs' lunch prices and children's birthday treats are shown in Table 2. Cross tabulations on the two municipal policies and the prevalence of ECEs eating the same lunch as the children and having birthday foods available in the preschool groups are found in Table 3. The prevalence of staff eating the same lunch as the children and having birthday treats available in the preschool groups varied greatly according to the municipal policy on the topic.

Table 4 presents the associations between neighborhood SES and feeding practices at preschools. The crude model showed that in high SES neighborhood preschools it was more likely that ECEs ate the same lunch as children and used food as a reward (Model 1). When adjusting for the ECE's educational level (Model 2) only the association for rewarding with food remained. The crude model also showed that in high SES neighborhood preschools it was more likely that children served themselves vegetables (borderline significant) and less likely that there were foods outside the menu available on birthdays. After controlling for the ECEs' educational level, only the difference regarding birthday foods remained significant between high SES and low SES groups. When additionally controlling for municipal policies (Model 3), all associations disappeared except for the association between neighborhood SES and rewarding with food.

\section{DISCUSSION}

In this study, we examined whether feeding practices in Finnish public preschools differed by preschool neighborhood SES. In the crude model, it was more likely that ECEs in high SES neighborhood preschools ate the same food as children and rewarded children with other food for eating vegetables. It was also less likely that foods outside the menu were available on birthdays. In the final model, adjusted for ECE's education and municipal policies on ECEs' 
lunches and on birthday treats, all the associations except one disappeared, suggesting that these municipal policies explain the examined preschool feeding practices more than neighborhood SES. Only the use of other food as a reward for eating vegetables remained associated with neighborhood SES.

Many studies in recent years have examined feeding practices at preschools [5-7, 10-12, 16, 26, 27]. The majority of these studies originate from the U.S. $[7,10-12,16,26,27]$ and a few from the Netherlands $[5,6]$. In these studies the prevalence of at least one ECE sitting with children varied from $29 \%$ to $81 \%[7,11,12,26]$ versus $95 \%$ in our study, eating (some of) the same food as the children varied from $36 \%$ to $66 \%[5,7,12,16,26]$ versus $90 \%$ in our study, and letting children serve themselves varied between $8 \%$ and $49 \%[5,7,10,11,27]$ versus $30 \%$ in our study. In this study, the high rates of sitting with the children and eating the same food as they can be explained by the legislation that obliges one ECE per group to eat a model lunch with the children. In addition, Finnish ECEs consider role modeling healthy eating very important [28].

We have found only one study examining the effects of preschool neighborhood SES on preschool feeding practices [15] and a few examining effects of certain supplemental preschool programs on feeding practices [16, 17]. Contrary to our results, Neelon et al. [15] found that in more deprived areas ECEs were more likely to sit with children during mealtimes and to encourage children to choose foods themselves. Possible reasons for these findings were not discussed. Two previous U.S. studies have found that being part of a supplemental program (e.g. Child and Adult Care Food Program) for healthy eating in preschools might mean that feeding practices at low SES preschools are more aligned with recommendations [16, 17]. In Finland, such programs do not exist, perhaps due to the high standardization of preschool functioning.

In this study, the associations found between neighborhood SES and feeding practices became weaker after controlling for ECEs' education and disappeared altogether after additionally controlling for municipal-level policies. The only exception was rewarding with food, which remained associated with high SES neighborhoods. This was surprising given that the other associations in Models 1 and 2 suggested that in high SES neighborhoods the feeding practices were more aligned with the recommendations. Perhaps ECEs in high SES neighborhoods put more effort in getting the children to eat vegetables, including through the use of this discouraged method. In the Finnish context, ECEs can reward the children only with quite healthy foods (food from the main course, milk, or crisp bread) as there are no sweet/snack foods generally available in preschools. 
We also found that municipal policies, preschool neighborhood SES, and feeding practices at preschools were all somewhat associated with each other. As expected, favorable municipal policies were associated with ECEs eating the same lunch as the children and birthday foods not being available. In addition, municipal policies and preschool neighborhood SES were borderline associated with each other. The results indicated that municipalities that included higher SES preschool neighborhoods also had policies that presumably lead to healthier food intake among children. These associations should be further studied with more appropriate samples. With regard to a Norwegian study that found that preschools with bigger food budgets serve more vegetables [29], economic resources and their allocation in the municipality may contribute largely to the food served at municipal preschools and possibly also feeding practices used by the ECEs.

Although income differences in Finland are among the smallest in the E.U. [30], socioeconomic differences in mortality, morbidity, and health behaviors are large in Finland [31, 32]. In addition, socioeconomic differences in food consumption and nutrient intake exist already in early childhood [4]. Thus, recognizing factors that contribute to these differences is important in order to be able to tackle them. Municipal preschools, although equal in theory, can contribute to these differences.

In Finland $87 \%$ of children who receive early childhood education, attend municipal preschools or municipal homebased childcare [2]. Thus, associations between neighborhood SES and preschool feeding practices might be stronger or different in countries where differences in income and educational levels between population groups are larger, and where private preschools with policies and practice that are more varied are more common. The existence of different childcare programs for the lowest socioeconomic groups can also influence these associations.

\section{Strengths and weaknesses}

The main strength of this study is that it is one of the first studies to examine socioeconomic differences between preschool neighborhoods and preschool feeding practices. Another strength is that some of the group-level practices were directly observed instead of being reported by ECEs, which decreases the possibility of social desirability bias. Although the participation rate among preschools was only moderate, the sample was quite heterogeneous in that it included both urban and rural preschools from different parts of Finland representing different SES neighborhoods and municipalities. In addition, the questionnaire response rate among ECEs was high. The study would have gained from a larger sample size, but as this was a secondary analysis of DAGIS study, power calculations were not done for the purposes of this study. We are aware that neighborhood SES as a proxy for preschool SES has its weaknesses, but 
compared to other options (such as using the SES of the DAGIS study participants, with participation rate of 27\%) we considered neighborhood SES as more broad and justifiable measure of preschool SES.

In this study, we have examined only a handful of feeding practices among many. The use of other research methods, such as video recordings of meal situations, could add useful knowledge on feeding practices in preschools. For example, interaction between the ECEs and the children would be of interest, but it is challenging to examine with quantitative methods.

\section{CONCLUSIONS}

This study is among the first to examine the associations between preschool neighborhood SES and feeding practices in preschools. Associations were found, but most socioeconomic differences disappeared when controlling for municipal policies on feeding practices. It is a positive finding that preschools mostly have equal feeding practices despite neighborhood SES. Further research should examine if similar associations hold in other contexts, and whether preschool feeding practices mediate associations between preschool municipal policies or neighborhood SES, and children's food intake. 


\section{ACKNOWLEDGEMENTS}

We thank the children, parents and preschools for their participation in this study. We also thank the DAGIS team for collecting the data.

\section{DECLARATION ON CONFLICT OF INTERESTS}

The authors declare that there is no conflict of interest.

\section{FUNDING}

This work was supported by Folkhälsan Research Center, University of Helsinki, The Ministry of Education and Culture in Finland, The Ministry of Social Affairs and Health, The Academy of Finland (Grant numbers: 285439, 287288, 288038), The Juho Vainio Foundation, the Signe and Ane Gyllenberg Foundation, The Finnish Cultural Foundation/South Ostrobothnia Regional Fund, the Päivikki and Sakari Sohlberg foundation, the Medicinska Föreningen Liv och Hälsa, Finnish Foundation for Nutrition Research and Finnish Food Research Foundation. 
Table 1. Descriptives of the early childhood educators (ECEs) and feeding practices in the preschool groups in DAGIS study. ( $\mathrm{SD}=$ standard deviation).

\begin{tabular}{|c|c|}
\hline & $\begin{array}{l}\% \text { or } \\
\text { mean } \\
\text { (SD) }\end{array}$ \\
\hline Questionnaire A (filled in by all ECEs) & N 378 \\
\hline Women & $97 \%$ \\
\hline Age, years & $42(11.6)$ \\
\hline \multicolumn{2}{|l|}{ Educational level } \\
\hline No qualification & $5 \%$ \\
\hline Vocational qualification & $51 \%$ \\
\hline Bachelor of social services/social pedagogue & $21 \%$ \\
\hline Kindergarten teacher or higher & $22 \%$ \\
\hline \multicolumn{2}{|l|}{ ECEs' lunch } \\
\hline Eat the same food as the children every weekday & $61 \%$ \\
\hline Eat the same food as the children 1-4 days a week & $8 \%$ \\
\hline Do not eat the same food as the children & $31 \%$ \\
\hline \multicolumn{2}{|l|}{$\begin{array}{l}\text { Knowledge of fruit and vegetable intake } \\
\text { recommendation for children }\end{array}$} \\
\hline Know the recommendation $(=5$ portions or more $)$ & $23 \%$ \\
\hline \multicolumn{2}{|l|}{ Using other food as a reward for eating vegetables } \\
\hline Never & $43 \%$ \\
\hline Rarely & $30 \%$ \\
\hline Sometimes & $20 \%$ \\
\hline Often & $5 \%$ \\
\hline Always & $2 \%$ \\
\hline Questionnaire B (filled in by one ECE per group) & $N 146$ \\
\hline Number of children in the group & $19(5.0)$ \\
\hline Number of ECEs in the group & $3.2(0.7)$ \\
\hline \multicolumn{2}{|l|}{ Food outside the menu on birthdays } \\
\hline Not available & $39 \%$ \\
\hline Available, but sugary foods restricted & $30 \%$ \\
\hline Available, sugary foods not restricted & $31 \%$ \\
\hline \multicolumn{2}{|l|}{$\begin{array}{l}\text { Children's participation in practical meal } \\
\text { preparations, e.g. setting the table }\end{array}$} \\
\hline Never & $19 \%$ \\
\hline
\end{tabular}




\begin{tabular}{|l|l|}
\hline $1-5$ times a year & $14 \%$ \\
\hline At least 6 times a year & $7 \%$ \\
\hline At least once a month & $7 \%$ \\
\hline At least once a week & $14 \%$ \\
\hline Daily & $39 \%$ \\
\hline Observation & $N \mathbf{1 3 3}$ \\
\hline Number of children present at lunch & $15.1(4.8)$ \\
\hline Number of ECEs present at lunch & $3.1(1.3)$ \\
\hline Number of tables the children sat in during lunch & $3.6(1.4)$ \\
\hline $\begin{array}{l}\text { Lunch situations where at least one ECE sat in all } \\
\text { children's lunch tables }\end{array}$ & $41 \%$ \\
\hline Vegetable/salad serving style* & \\
\hline Children served themselves & \\
\hline ECEs served & $30 \%$ \\
\hline
\end{tabular}

*Vegetables/salad was served on 122 lunch situations. Lunches without salad/vegetables were soup lunches where usually fruit was served. 
Table 2. Preschool neighborhood socioeconomic status and municipal policies on early childhood educators' (ECE) lunch prices and children's birthday treats (chi-squared test).

\begin{tabular}{|l|l|l|l|}
\hline & & $\begin{array}{l}\text { Municipal policy } \\
\text { on ECEs lunch } \\
\text { prices }\end{array}$ & $\begin{array}{l}\text { Municipal policy on } \\
\text { children's birthday } \\
\text { treats }\end{array}$ \\
\hline & $\begin{array}{l}\text { All ECEs get } \\
\text { lunch with its } \\
\text { taxable value }\end{array}$ & $\begin{array}{l}\text { Children are not } \\
\text { allowed to bring } \\
\text { birthday treats to be } \\
\text { shared with other } \\
\text { children }\end{array}$ \\
\hline Preschool neighborhood SES & Low & $50 \%$ & $18 \%$ \\
\hline & Middle & $68 \%$ & $36 \%$ \\
\hline & High & $82 \%$ & \begin{tabular}{l}
$50 \%$ \\
\hline
\end{tabular} \\
\hline & $\begin{array}{l}\mathrm{X}^{2}=5.05 \\
\mathrm{Df}=2 \\
\mathrm{p}=0.08\end{array}$ & $\begin{array}{l}\mathrm{X}^{2}=4.94 \\
\mathrm{Df}=2 \\
\mathrm{p}=0.09\end{array}$ \\
\hline
\end{tabular}

Table 3. Municipal policies and early childhood educators' (ECE) lunch and birthday treat practices (chi-squared test).

\begin{tabular}{|c|c|c|}
\hline & & $\begin{array}{l}\text { ECEs who eat } \\
\text { the same lunch } \\
\text { as the children }\end{array}$ \\
\hline \multirow[t]{4}{*}{$\begin{array}{l}\text { Municipal policy on } \\
\text { ECEs' lunch prices }\end{array}$} & $\begin{array}{l}\text { All ECEs get lunch with } \\
\text { taxable value }\end{array}$ & $83 \%$ \\
\hline & $\begin{array}{l}\text { Not all ECEs get lunch } \\
\text { with taxable value }\end{array}$ & $43 \%$ \\
\hline & & $\begin{array}{l}X^{2}=63.53 \\
D f=1 \\
P<0.001\end{array}$ \\
\hline & & $\begin{array}{l}\text { Birthday foods } \\
\text { available }\end{array}$ \\
\hline \multirow[t]{3}{*}{$\begin{array}{l}\text { Municipal policy on } \\
\text { children's birthday } \\
\text { treats }\end{array}$} & $\begin{array}{l}\text { Children are not allowed } \\
\text { to bring birthday treats } \\
\text { to each other }\end{array}$ & $21 \%$ \\
\hline & $\begin{array}{l}\text { Children are allowed to } \\
\text { bring birthday treats to } \\
\text { each other }\end{array}$ & $90 \%$ \\
\hline & & $\begin{array}{l}X^{2}=69.46 \\
D f=1 \\
P<0.001\end{array}$ \\
\hline
\end{tabular}


Table 4. Logistic regression analysis for associations between preschool neighborhood socioeconomic status (SES) and feeding practices. Odds ratios (OR) and 95\% confidence intervals (CI).

\begin{tabular}{|c|c|c|c|c|}
\hline \multirow[b]{2}{*}{ Dependent variables } & \multirow[b]{2}{*}{$\begin{array}{l}\text { Neighborhood } \\
\text { SES }\end{array}$} & \multicolumn{3}{|c|}{ OR $(95 \%$ CI $)$} \\
\hline & & Model 1 & Model 2 & Model 3 \\
\hline \multirow[t]{3}{*}{$\begin{array}{l}\text { ECE knows the national } \\
\text { recommendation on fruit and }\end{array}$} & Low & 1 & 1 & 1 \\
\hline & Middle & $0.73(0.41-1.30)$ & $0.72(0.38-1.38)$ & $0.75(0.39-1.44)$ \\
\hline & High & $0.62(0.35-1.10)$ & $0.60(0.33-1.10)$ & $0.60(0.33-1.10)$ \\
\hline $\begin{array}{l}\text { ECE eats the same lunch as the } \\
\text { children }\end{array}$ & Low & 1 & 1 & 1 \\
\hline \multirow[t]{2}{*}{ (at least once a week vs. less often) } & Middle & $1.58(0.93-2.69)$ & $1.40(0.60-3.29)$ & $0.88(0.41-1.86)$ \\
\hline & High & $2.46(1.42-4.24)$ & $2.16(0.93-5.02)$ & $1.07(0.44-2.60)$ \\
\hline \multirow[t]{3}{*}{$\begin{array}{l}\text { There is at least one ECE sitting in all } \\
\text { lunch tables }\end{array}$} & Low & 1 & 1 & 1 \\
\hline & Middle & $2.18(0.72-6.54)$ & $2.27(0.75-6.89)$ & $1.94(0.59-6.35)$ \\
\hline & High & $2.01(0.77-5.24)$ & $1.87(0.71-4.88)$ & $1.41(0.55-3.62)$ \\
\hline \multirow{3}{*}{$\begin{array}{l}\text { ECE rewards the children with more } \\
\text { popular food for eating vegetables } \\
\text { (at least sometimes vs. rarely or } \\
\text { never) }\end{array}$} & Low & 1 & 1 & 1 \\
\hline & Middle & $1.79(0.98-3.26)$ & $1.79(0.95-3.39)$ & $1.60(0.83-3.06)$ \\
\hline & High & $2.48(1.40-4.41)$ & $2.47(1.27-4.82)$ & $2.13(1.12-4.07)$ \\
\hline \multirow[t]{3}{*}{ Children self-serve vegetables/salad } & Low & 1 & 1 & 1 \\
\hline & Middle & $1.72(0.61-4.84)$ & $1.75(0.53-5.83)$ & $1.24(0.43-3.60)$ \\
\hline & High & $2.64(0.98-7.11)$ & $2.42(0.79-7.38)$ & $1.52(0.50-4.63)$ \\
\hline \multirow[t]{3}{*}{$\begin{array}{l}\text { Foods outside the menu are available } \\
\text { on birthdays }\end{array}$} & Low & 1 & 1 & 1 \\
\hline & Middle & $0.57(0.23-1.44)$ & $0.63(0.19-2.03)$ & $1.71(0.39-7.54)$ \\
\hline & High & $0.29(0.12-0.71)$ & $0.31(0.10-0.95)$ & $0.72(0.23-2.30)$ \\
\hline \multirow[t]{3}{*}{$\begin{array}{l}\text { Children participate in practical meal } \\
\text { preparations daily }\end{array}$} & Low & 1 & 1 & 1 \\
\hline & Middle & $0.95(0.40-2.22)$ & $1.00(0.41-2.41)$ & $0.88(0.34-2.28)$ \\
\hline & High & $0.87(0.38-2.02)$ & $0.92(0.40-2.09)$ & $0.78(0.30-1.97)$ \\
\hline
\end{tabular}

$\overline{\mathrm{ECE}}=$ early childhood educator

Model 1: no adjustments

Model 2: adjusted with ECE's education

Model 3: adjusted with ECE's educational level, municipal policy on ECEs' lunch prices and municipal policy on children's birthday treats. 
References

[1] OECD - Social Policy Division - Directorate of Employment, Labour and Social Affairs. OECD Family Database, PF 3.2: Enrolment in childcare and pre-school. Available at:

http://www.oecd.org/els/soc/PF3_2_Enrolment_childcare_preschool.pdf (accessed 11/18 2016).

[2] Kuoppala T and Säkkinen S. Lasten päivähoito 2014. Report no. tilastoraportti 28/2015.

[3] Craigie AM, Lake AA, Kelly SA, et al. Tracking of obesity-related behaviours from childhood to adulthood: A systematic review. Maturitas 2011; 70: 266-284.

[4] Kyttala P, Erkkola M, Lehtinen-Jacks S, et al. Finnish Children Healthy Eating Index (FCHEI) and its associations with family and child characteristics in pre-school children. Public Health Nutr 2014; 17: 2519-2527.

[5] Gubbels JS, Kremers SP, Stafleu A, et al. Child-care environment and dietary intake of 2- and 3-year-old children. J Hum Nutr Diet 2010; 23: 97-101.

[6] Gubbels JS, Gerards SM and Kremers SP. Use of food practices by childcare staff and the association with dietary intake of children at childcare. Nutrients 2015; 7: 2161-2175.

[7] Kharofa RY, Kalkwarf HJ, Khoury JC, et al. Are Mealtime Best Practice Guidelines for Child Care Centers Associated with Energy, Vegetable, and Fruit Intake?. Child Obes 2016; 12: 52-58.

[8] Valtion ravitsemusneuvottelukunta. Terveyttä ja iloa ruoasta - varhaiskasvatuksen ruokailusuositus. Helsinki: Helsinki, 2018.

[9] American Academy of Pediatrics, American Public Health Association, National Resource Center for Health and Safety in Child Care. Caring for Our Children: National Health and Safety Performance Standards: Guidelines for Early Care and Education Programs. 3rd ed. Washington: Washington, 2011.

[10] Sisson SB, Campbell JE, May KB, et al. Assessment of food, nutrition, and physical activity practices in Oklahoma child-care centers. J Acad Nutr Diet 2012; 112: 1230-1240.

[11] Sigman-Grant M, Christiansen E, Branen L, et al. About feeding children: mealtimes in child-care centers in four western states. J Am Diet Assoc 2008; 108: 340-346.

[12] Nanney MS, LaRowe TL, Davey C, et al. Obesity Prevention in Early Child Care Settings: A Bistate (Minnesota and Wisconsin) Assessment of Best Practices, Implementation Difficulty, and Barriers. Health Educ Behav 2016.

[13] Kremers SP. Theory and practice in the study of influences on energy balance-related behaviors. Patient Educ Couns 2010; 79: 291-298.

[14] Bussell K, Francis L, Armstrong B, et al. Examining Nutrition and Physical Activity Policies and Practices in Maryland's Child Care Centers. Child Obes 2018; 14: 403-411.

[15] Neelon SE, Burgoine T, Hesketh KR, et al. Nutrition practices of nurseries in England. Comparison with national guidelines. Appetite 2015; 85: 22-29.

[16] Liu ST, Graffagino CL, Leser KA, et al. Obesity Prevention Practices and Policies in Child Care Settings Enrolled and Not Enrolled in the Child and Adult Care Food Program. Matern Child Health J 2016; 20: 1933-1939.

[17] Sigman-Grant M, Christiansen E, Fernandez G, et al. Child care provider training and a supportive feeding environment in child care settings in 4 states, 2003. Prev Chronic Dis 2011; 8: A113. 
[18] Singh GK and Ghandour RM. Impact of neighborhood social conditions and household socioeconomic status on behavioral problems among US children. Matern Child Health J 2012; 16 Suppl 1: S158-69.

[19] Maatta S, Lehto R, Nislin M, et al. Increased health and well-being in preschools (DAGIS): rationale and design for a randomized controlled trial. BMC Public Health 2015; 15: 402-015-1744-z.

[20] Lehto E, Ray C, Vepsalainen H, et al. Increased Health and Wellbeing in Preschools (DAGIS) Study-Differences in Children's Energy Balance-Related Behaviors (EBRBs) and in Long-Term Stress by Parental Educational Level. Int J Environ Res Public Health 2018; 15: 10.3390/ijerph15102313.

[21] National Institute for Health and Welfare. The Welfare Compass for Monitoring Regional Welfare. Available at: https://www.hyvinvointikompassi.fi/en/web/hyvinvointikompassi/etusivu (accessed 9/2014).

[22] Statistics Finland. Grid database. Available at: https://www.stat.fi/tup/ruututietokanta/index_en.html (accessed $11 / 18$ 2016).

[23] Halonen JI, Kivimaki M, Pentti J, et al. Quantifying neighbourhood socioeconomic effects in clustering of behaviour-related risk factors: a multilevel analysis. PLoS One 2012; 7: e32937.

[24] Ward D, Hales D, Haverly K, et al. An instrument to assess the obesogenic environment of child care centers. Am J Health Behav 2008; 32: 380-386.

[25] Muthén LK and Muthén BO. Mplus User's Guide. Eight edition ed. Los Angeles, CA: Los Angeles, CA, 19982012.

[26] Nahikian-Nelms M. Influential factors of caregiver behavior at mealtime: a study of 24 child-care programs. J Am Diet Assoc 1997; 97: 505-509.

[27] Benjamin Neelon SE, Vaughn A, Ball SC, et al. Nutrition practices and mealtime environments of North Carolina child care centers. Child Obes 2012; 8: 216-223.

[28] Ray C, Maatta S, Lehto R, et al. Influencing factors of children's fruit, vegetable and sugar-enriched food intake in a Finnish preschool setting - Preschool personnel's perceptions. Appetite 2016; 103: 72-79.

[29] Himberg-Sundet A, Kristiansen AL, Bjelland M, et al. Is the environment in kindergarten associated with the vegetables served and eaten? The BRA Study. Scand J Public Health 2018: 1403494818756702.

[30] Statistics Finland. Income differences in Europe in 2012. Available at:

http://www.stat.fi/til/tjt/2013/04/tjt_2013_04_2015-05-25_kat_001_fi.html (accessed 11/18 2016).

[31] Lahelma E, Pietilainen O, Ferrie J, et al. Changes Over Time in Absolute and Relative Socioeconomic Differences in Smoking: A Comparison of Cohort Studies From Britain, Finland, and Japan. Nicotine Tob Res 2016; 18: 1697-1704.

[32] Mackenbach JP, Bos V, Andersen O, et al. Widening socioeconomic inequalities in mortality in six Western European countries. Int J Epidemiol 2003; 32: 830-837. 